\title{
Three-dimensional proton magnetic resonance spectroscopy and diffusion-weighted imaging in the differentiation of incidental prostate carcinoma from benign prostate hyperplasia
}

\author{
XUE-QIN ZHANG $^{1 *}$, XIANG-RONG YU ${ }^{2 *}$, ZHONG-LI DU $^{2}$, XIAO-FEN MIAO ${ }^{1}, J_{A N}$ LU $^{1}$ and QUAN ZHOU ${ }^{3}$ \\ ${ }^{1}$ Department of Radiology, The Third People's Hospital of Nantong, Nantong, Jiangsu 226006; \\ ${ }^{2}$ Department of Radiology, Zhuhai Hospital of Jinan University, Zhuhai People's Hospital, Zhuhai, Guangdong 519000; \\ ${ }^{3}$ Department of Radiology, The First Affiliated Hospital of Jinan University, Guangzhou, Guangdong 510000, P.R. China
}

Received September 18, 2016; Accepted January 17, 2018

DOI: $10.3892 / \mathrm{ol} .2018 .8131$

\begin{abstract}
The present study evaluated three-dimensional proton magnetic resonance spectroscopy (MRS) and diffusion-weighted imaging (DWI) features in differentiating incidental prostate carcinoma (IPCa) and benign prostate hyperplasia (BPH) in the central gland of the prostate. The clinical and imaging data of 9 patients with IPCa, 118 patients with BPH [including those with glandular hyperplasia $(\mathrm{GH})$, stromal hyperplasia ( $\mathrm{SH})$ and mixed hyperplasia $(\mathrm{MH})]$, were retrospectively analyzed. The mean (choline + creatine)/citrate $(\mathrm{CC} / \mathrm{C})$ value of 3D MRS, the apparent diffusion coefficient (ADC) value and the minimal ADC value of DWI were compared between carcinoma and non-carcinoma tissues. The mean $\mathrm{CC} / \mathrm{C}$ values were $1.04 \pm 0.28$, and $1.09 \pm 0.58$ in IPCa and $\mathrm{BPH}$, respectively $(\mathrm{t}=-0.205, \mathrm{P}=0.838)$. No significant difference in $\mathrm{CC} / \mathrm{C}$ values $\left(\chi^{2}=2.595, \mathrm{P}=0.458\right)$ could be detected between IPCa, GH, SH and MH groups. The ADC values of the central gland only differed between IPCa $(1.48 \pm 0.18) \times 10^{-3}$ and $\mathrm{GH}(1.60 \pm 0.16) \times 10^{-3} \mathrm{~mm}^{2} / \mathrm{sec}(\mathrm{P}=0.037)$. The minimal ADC values were similar between IPCa $(1.15 \pm 0.10) \times 10^{-3}$ and BPH $(1.14 \pm 0.11) \times 10^{-3} \mathrm{~mm}^{2} / \mathrm{sec}$, no significant differences could be detected between IPCa and $\mathrm{GH}(\mathrm{P}=0.930)$, IPCa and $\mathrm{SH}(\mathrm{P}=0.192)$, and IPCa and $\mathrm{MH}(\mathrm{P}=0.544)$. Although
\end{abstract}

Correspondence to: Dr Jian Lu, Department of Radiology, The Third People's Hospital of Nantong, 99 Qingnian Road, Nantong, Jiangsu 226006, P.R. China

E-mail: drlujian@163.com

Dr Quan Zhou, Department of Radiology, The First Affiliated Hospital of Jinan University, 613 West Huangpu Road, Guangzhou, Guangdong 510000, P.R. China

E-mail: drzhouquan@163.com

${ }^{*}$ Contributed equally

Key words: incidental prostate carcinoma, magnetic resonance imaging, magnetic resonance spectroscopy, diffusion-weighted imaging the ADC values of the central gland of the prostate differed between IPCa and GH, the findings of the present study therefore indicate that combining 3D MRS with DWI cannot potentially improve the detection of IPCa.

\section{Introduction}

Incidental prostate cancer (IPCa) is diagnosed incidentally from the histopathological examination of specimens obtained at the time of transurethral resection of the prostate (TURP) or adenomectomy intended to treat benign prostatic hyperplasia (BPH). Although the majority of cases of IPCa are clinically insignificant, the biological behavior of IPCa may change, and the speed of progression of individuals remains unpredictable (1). Therefore, the accurate preoperative identification of IPCa is of great importance, as these patients would benefit the most from an appropriate treatment for IPCa.

Recently, multi-parametric magnetic resonance imaging (MRI) techniques, including T2-weighted imaging (T2WI), magnetic resonance spectroscopy (MRS) and diffusion-weighted MRI (DWI), are useful tools for the diagnosis of prostatic diseases, including the central gland (CG) and peripheral zone (PZ) of the prostate. The results of prior studies (2-12) indicate that the apparent diffusion coefficient (ADC) value of malignant regions was lower than that of the benign regions, and the [choline $(\mathrm{Cho})+$ creatine $(\mathrm{Cre})] /$ citrate (Cit) $(\mathrm{CC} / \mathrm{C})$ value of the former was higher than the latter.

There are a number of studies concerning the morphological and functional parameters of MRI on the CG and PZ of clinical prostate cancer (4-12); however, to the best of our knowledge, no public literature concerning MRS and DWI in IPCa in the CG of the prostate. The present study aimed to investigate the differences in conventional MRI manifestation, $\mathrm{CC} / \mathrm{C}$ value, and ADC value between IPCa and $\mathrm{BPH}$, and whether there are benefits to using these techniques to differentiate between the two diseases.

\section{Materials and methods}

Patients. Informed consent was waived by the Nantong Medical Institutional Review Board for this retrospective study. All 
patients who underwent MRI of the prostate (T1WI, T2WI, MRS and DWI) between July 2006 and March 2013 in the radiological database of the Third People's Hospital of Nantong were retrospectively reviewed. In total, 164 patients who had been diagnosed as BPH on MRI then underwent TURP were collected.

A total of 9 patients were postoperatively diagnosed with IPCa, (mean age, $73.56 \pm 5.18$ years; range, 66-84 years). Mean total-prostate specific antigen (T-PSA), $10.87 \pm 4.80 \mathrm{ng} / \mathrm{ml}$; range, $5.19-20.97 \mathrm{ng} / \mathrm{ml}$. Gleason scores (13) varied from 2 to 7 , including lower scores ( 2 or 3 or 4 ) in 3 cases $(33 \%)$ and higher certainty scores ( 5 or 6 or 7 ) in 6 of the 9 patients (67\%) with IPCa. Among these 9 patients with MRI imaging, 7 exhibited MRS and 8 exhibited DWI.

A total of 155 patients were definitively diagnosed with BPH following surgery, of whom 118 underwent MRS or DWI before operations (mean age, 69.38 \pm 6.43 years; range, $55-87$ years). Mean T-PSA $14.39 \pm 11.51 \mathrm{ng} / \mathrm{ml}$, range 0.75-92.50 ng/ml. Preoperative MRS was performed in 99 patients, including 7 cases of glandular hyperplasia $(\mathrm{GH})$, 30 cases of stromal hyperplasia ( $\mathrm{SH}), 62$ cases of mixed hyperplasia $(\mathrm{MH})$. In total, 85 patients underwent preoperative DWI, which revealed that there were 7 cases of GH, 18 cases of $\mathrm{SH}$ and 63 cases of $\mathrm{MH}$.

MRI. All MRIs were performed using GE 1.5 SignaTwinSpeed magnetic resonance scanner (GE Healthcare, Chicago, IL, USA).

Conventional MR scan. The patients were examined using a body coil for excitation and an abdominal phased array coil for reception. A fast spin-echo (FSE) T2WI was applied with the following parameters: Repetition time/echo time (TR/TE), $3,500 / 85$ msec; echo train length (ETL), 19; slice thickness/gap 5/0.5 mm; field of view (FOV), 24x24 cm; number of excitations (NEX), 4; matrix, 320x256. The parameters of T1WI were as follows: TR/TE, 450/12 ms; slice thickness/gap, 5/0.5 mm, FOV 24x24 cm; NEX, 2; matrix, 256x192.

$3 D{ }^{l} H$-MRS scan. Before April 2008, patients were scanned using FSE T2WI with an endorectalcoil (TR/TE, 3,500/85 msec; ETL, 19; slice thickness/gap, 3/0 mm; FOV, $13 \times 13 \mathrm{~cm}$; NEX, 4; matrix, 320x256). There sulting images were used as a scanogram of 3D ${ }^{1} \mathrm{H}-\mathrm{MRS}$ examination and images were integrated with metabolic and anatomical information. A 3D ${ }^{1} \mathrm{H}-\mathrm{MRS}$ examination was performed using the prostate spectroscopy and imaging examination (PROSE) sequence (TR/TE, 1,000/130 msec; FOV, 11x11 cm; NEX, 1; matrix, 16x8; scanning time, 17-19 min). The axial images were used to guide the positioning of the spectroscopic volume of interest. This volume was selected to maximize coverage of prostate while minimizing the inclusion of periprostatic fat and rectal air. In the axial plane, the saturated zone was added on to the edge of the region of interest to eliminate the effects of fat tissues around the rectanglular region of interest and endorectal gas at the rear of prostate. The conventional automatic pre-scan was performed prior to collection of MRS data, including automatic shimming and water suppression; full width half maximum was usually $<15 \mathrm{~Hz}$ for collecting MRS data. After April 2008, patients were scanned using FSE
T2WI with a body coil line. 3D ${ }^{1} \mathrm{H}-\mathrm{MRS}$ examination was performed using PROSE sequence (TR/TE, 1,000/130 msec; FOV, 11x11 cm; NEX, 10; matrix, 12x8; total scan time, $16 \min 4 \mathrm{sec})$.

DWI scan. A single-shot EPI sequence was used, with b values of 0 and $800 \mathrm{sec} / \mathrm{mm}^{2}$. Before February 2006, the body coil was used as the receiver coil (TR/TE 3,000/6.6 msec; slice thickness/gap, 6/0 mm; FOV, 26x26 cm; NEX, 2; matrix, 96x96; scan time, $24 \mathrm{sec}$ ). After February 2006, the abdominal phased array coil was used as the receiving coil (TR/TE, 3,500/56.4 msec; slice thickness/gap, 6/0 mm; FOV, 26x26 cm; NEX, 4; matrix, 128x128; scan time, $56 \mathrm{sec}$ ).

\section{Imaging analysis}

$M R S$. The criteria of usable MRS voxels was as follows: i) At least $75 \%$ of the voxel was located in the central gland, and had not been polluted by the signals from unsuppressed water and fat; ii) the urethra and periurethral glands were not included; and iii) the signal-to-noise ratio of three main metabolites, Cho, Cre and Cit, in each spectrum was $>3$.

$D W I$. ADC values in each slice of the central gland of each patient (the ADC values of the central gland) and minimal ADC value in the central glands (the minimal ADC values) were measured. The region of interest (ROI) placement guidelines for the central gland ADC values were as follows: The largest ROI of central gland in all scanning planes was hand-painted, the ROI edges were as far as possible consistent with the edges of the central gland. The ROI placement guidelines for the minimal ADC value were as follows: i) The ROI was placed in the central gland where the ADC value was lowest (referring to the ADC map); ii) the junction area of the peripheral zone, the central zone, the urethra, blood vessels, hemorrhage or calcification were avoided; and iii) ROI was oval with an area of $30-50 \mathrm{~mm}^{2}$.

Statistical analysis. All data were statistically analyzed using SPSS16.0 software (SPSS, Inc., Chicago, IL, USA). All data were expressed as mean \pm standard deviation. The group data were firstly tested to assess whether they were distributed normally. The independent-samples t-test was used to compare data between two groups. Levene's test was first used to compare between data among three groups, with the data that met the homogeneity of variance were compared using the $\chi^{2}$ test of variance, the data which did not meet the homogeneity of variance were compared using the Kruskal-Wallis $\mathrm{H}$-test. $\mathrm{P}<0.05$ was considered to indicate a statistically significant difference.

\section{Results}

Manifestation of IPCa on conventional MRI and DWI Conventional MRI findings. A total of 9 patients exhibited prostate enlargement to varying degrees, observed by T2WI, which was more evident in the central gland with mixed signal intensity, different numbers of hyperplastic nodules with hyperintensity or hypointensity were visible, the peripheral zone was compressed and thinned; 4 patients exhibited homogeneous hypointensity on T1WI imaging, 5 patients exhibited punctate hyperintensity within the hypointensity area, which were 
Table I. CC/C, ADC values of the central gland and the minimal ADC values of IPCa and BPH (including GH, SH and MH).

\begin{tabular}{lrrrrr}
\hline Group & $\mathrm{n}$ & CC/C value & $\mathrm{n}$ & Central gland ADC value & Minimal ADC value \\
\hline $\mathrm{IPCa}$ & 7 & $1.04 \pm 0.28$ & 8 & $1.48 \pm 0.18$ & $1.15 \pm 0.10$ \\
$\mathrm{BPH}$ & 99 & $1.09 \pm 0.58$ & 88 & $1.49 \pm 0.14$ & $1.14 \pm 0.11$ \\
$\mathrm{GH}$ & 7 & $0.99 \pm 0.05$ & 7 & $1.60 \pm 0.16$ & $1.21 \pm 0.12$ \\
$\mathrm{SH}$ & 30 & $1.31 \pm 0.94$ & 18 & $1.37 \pm 0.10$ & $1.15 \pm 0.06$ \\
$\mathrm{MH}$ & 62 & $0.99 \pm 0.31$ & 63 & $1.48 \pm 0.12$ & $1.12 \pm 0.10$ \\
\hline
\end{tabular}

$\mathrm{CC} / \mathrm{C}$, (choline + creatine)/citrate; ADC, apparent diffusion coefficient; IPCa, incidental prostate carcinoma; BPH, benign prostate hyperplasia; $\mathrm{GH}$, glandular hyperplasia; $\mathrm{SH}$, stromal hyperplasia; $\mathrm{MH}$, mixed hyperplasia. ADC unit, $\mathrm{x}^{-3} 0^{-3} \mathrm{~mm}^{2} / \mathrm{sec}$.

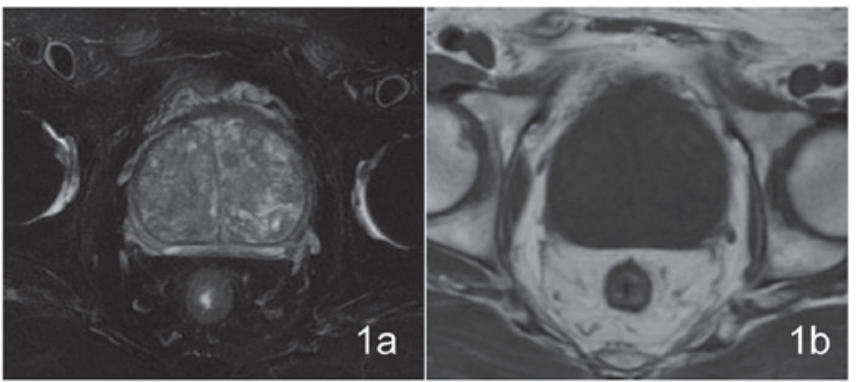

Figure 1. A 76-year-old man with incidental prostate carcinoma. (A) The central gland displayed mixed signal intensity on T2WI. (B) The center gland exhibited homogeneous hypointensity on T1WI. T2WI, T2-weighted imaging.

considered to be due to bleeding (Fig. 1). The pelvis and vertebral body exhibited no abnormal signal within the scan range and no lymph node enlargement was observed in the pelvic or groin areas. Patients were all diagnosed as BPH preoperatively by MRI. IPCa did not exhibit areas of clear high signal intensity on DWI.

Analysis of 3DMRS and DWI Data. Results of 3DMRS and DWI are depicted in Table I.

$C C / C$ values. There was no significant difference $(\mathrm{t}=-0.205$, $\mathrm{P}=0.838$ ) between $\mathrm{CC} / \mathrm{C}$ values of the IPCa and $\mathrm{BPH}$ groups. No significant difference $\left(\chi^{2}=2.595, \mathrm{P}=0.458\right)$ could be detected among the IPCa, GH, SH and MH groups (Fig. 2).

$A D C$ values of the central glands. There was no significant difference ( $\mathrm{t}=-0.224, \mathrm{P}=0.823)$ between the two groups of IPCa and BPH. There was a statistically significant $(\mathrm{F}=6.181$, $\mathrm{P}=0.001$ ) difference between the IPCa, $\mathrm{GH}, \mathrm{SH}$ and $\mathrm{MH}$ groups Of the four groups, the difference was statistically significant between the IPCa and the GH $(\mathrm{P}=0.037)$, in comparison of the IPCa and $\mathrm{SH}(\mathrm{P}=0.127)$, IPCa and $\mathrm{MH}(\mathrm{P}=0.908)$, no significant differences could be detected (Fig. 3).

Minimal ADC values. No statistically significant difference existed between the IPCa and $\mathrm{BPH}$ groups $(\mathrm{t}=0.139, \mathrm{P}=0.890)$. The difference in the minimal ADC values among the four groups was statistically significant $(\mathrm{F}=2.897, \mathrm{P}=0.039)$. No significant differences could be detected between IPCa and $\mathrm{GH}(\mathrm{P}=0.930)$, IPCa and SH $(\mathrm{P}=0.192)$, and IPCa and MH $(\mathrm{P}=0.544)$ (Fig. 4).

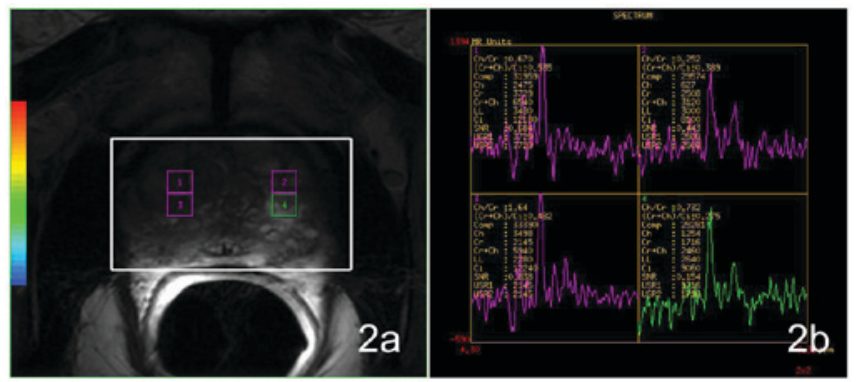

Figure 2. A 76-year-old man with incidental prostate carcinoma. (A) The voxels and (B) corresponding MRS map, the $\mathrm{CC} / \mathrm{C}$ values of the four voxels were $0.535,0.389,0.482$ and 0.275 , respectively.

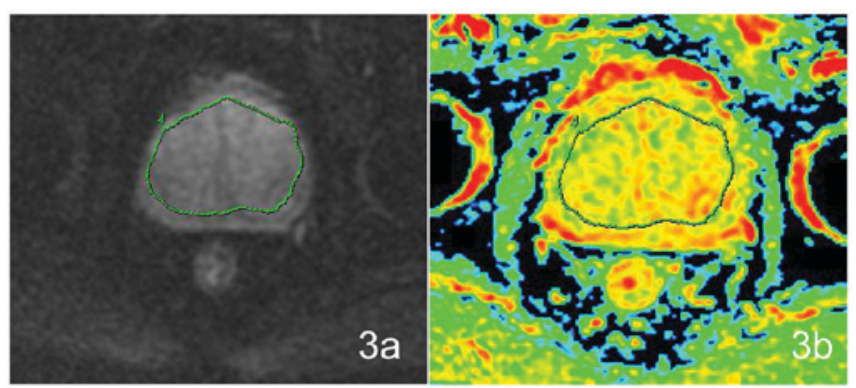

Figure 3. A 76-year-old man with incidental prostate carcinoma. (A) ROI of the ADC value of the central gland and (B) corresponding ADC map, the $\mathrm{ADC}$ value was $1.59 \times 10^{-3} \mathrm{~mm}^{2} / \mathrm{sec}$. ADC, apparent diffusion coefficient.

\section{Discussion}

As the non-invasive functional MRI, MRS and DWI techniques are not influenced by the experience of the operator and are conducive to improving the diagnostic efficacy (14-18), and serve an important role in the detection, localization, and staging of prostate cancer (9).

IPCa refers to that patients have been clinically diagnosed with $\mathrm{BPH}$, with no evidence of prostate cancer upon digital rectal examination or various imaging examinations. After undergoing open prostatectomy or TURP, the prostate cancer tissues were found in the inspection samples. There was a remarkable difference in morbidity between domestic and abroad reports (19-22). In this study, out of 164 patients who were diagnosed as BPH by MR examination after TURP, 155 patients were confirmed as BPH, 9 patients were confirmed 


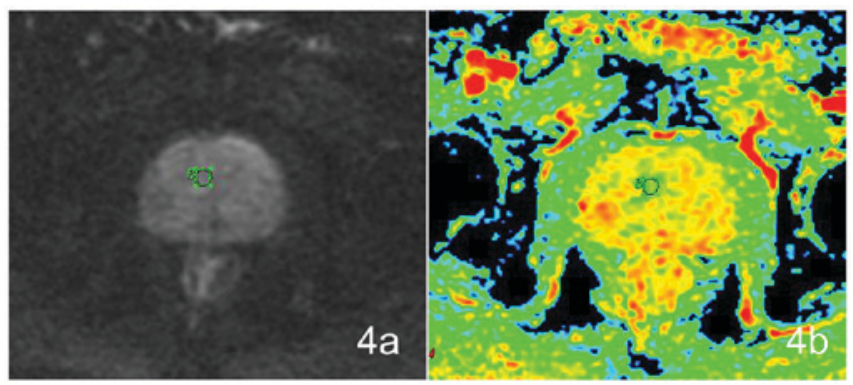

Figure 4. A 76-year-old man with incidental prostate carcinoma. (A) Region of interest of the minimal ADC value and (B) corresponding ADC map, the ADC value was $1.30 \times 10^{-3} \mathrm{~mm}^{2} / \mathrm{sec}$. ADC, apparent diffusion coefficient.

as IPCa, accounting for $5.49 \%$. The group of 9 patients with IPCa had the following characteristics: i) PSA levels were increased slightly compared with those with $\mathrm{BPH}$; and ii) tumors had low Gleason scores and they were mostly well-or moderately differentiated carcinomas.

Cancer in the CG of the prostate exhibits the following features: Homogeneous low signal intensity on T2WI, lack of capsule, ill-defined margins, increased $\mathrm{CC} / \mathrm{C}$ value, high signal intensity on DWI and decreased ADC value $(2,3,8,12,23)$. In the present study, the T1WI and T2WI findings for the 9 patients with IPCa were similar to those with BPH, and did not exhibit any apparently cancerous areas. As such, they were all preoperatively diagnosed as $\mathrm{BPH}$ by MRI.

The $\mathrm{CC} / \mathrm{C}$ value of IPCa and BPH was not significantly different in the present study. Furthermore, no significant difference in either the ADC value of the central gland or the minimal ADC value were identified. According to the pathological findings, the BPH group was divided into 3 subgroups: $\mathrm{GH}, \mathrm{SH}$ and $\mathrm{MH}$. Compared with IPCa, the differences in $\mathrm{CC} / \mathrm{C}$ values were not statistically significant, and the IPCa $\mathrm{CC} / \mathrm{C}$ value was lower than that of $\mathrm{SH}$, and slightly higher than those of $\mathrm{GH}$ and $\mathrm{MH}$; the $\mathrm{CC} / \mathrm{C}$ value of IPCa was between those of BPH groups. There was only statistically significant difference in ADC value, which was between IPCa and GH; there were no statistically significant differences in minimal $\mathrm{ADC}$ value between IPCa and various $\mathrm{BPH}$ groups. It was therefore clear that the $\mathrm{CC} / \mathrm{C}$ value and the $\mathrm{ADC}$ value of IPCa were close to those of BPH groups, which indicated at the difficulties of preoperative MRI diagnosis.

Previous studies reported that the $\mathrm{CC} / \mathrm{C}$ and ADC values of benign prostate disease were significantly different from those of prostate cancer $(3,24-27)$. As only the proportion of glandular and stromal tissue was changed in $\mathrm{BPH}$, which would not have a significant impact on the secretory function of the gland, These pathological features were different from clinically detected prostate cancer. In addition, Montironi et al reported that the staging, positive surgical margin rate, Gleason score and invasiveness of IPCa were lower than those of the clinically detected prostate cancer $(28,29)$, which indicated that IPCa is less aggressive compared with clinically detected cancer.

According to a previous study (3), GH exhibited hyperintensity on T2WI, with pathology revealing that it contained a large number of dilated glandular ducts and retention cysts and fewer stromal components. SH exhibited hypointensity, with pathology revealing that the hyperplastic nodules contained more collagen and stromal cells (including fibroblasts and smooth muscle cells) and fewer glandular components (3). The ADC value of the prostate gland tissue was higher than that of the prostate stromal tissue (30). Notably, the pathological findings of the present study revealed the presence of 7 cases of $\mathrm{GH}, 18$ cases of $\mathrm{SH}$ and 63 cases of $\mathrm{MH}$, all displayed asymmetrical enlargement of central glands with heterogeneous nodules on T2WI. On the ADC images, 4 cases (4/7) of GH had hyperintensity, 12 cases (12/18) of SH exhibited considerable hypointensity, measured using two methods of the central gland ADC values and the minimal ADC value. SH is formed of a greater cellular component, is more dense and containsless extracellular fluid than $\mathrm{GH}$; these differences could explain the smaller ADCs in SH, in accordance with the findings of a previous study (3).

In addition, a prior report indicated that metabolic performance of SH could be similar to that of atypical prostate cancer (31); the results of a present study were similar. The $\mathrm{CC} / \mathrm{C}$ value of the $\mathrm{SH}$ group was the highest of the four groups assessed in the current study. In the preoperative MRI diagnosis, the $\mathrm{CC} / \mathrm{C}$ values for certain $\mathrm{SH}$ cases were significantly increased, reaching a maximal value of 8 , providing evidence of the metabolic characteristics of typical prostate cancer, and leading to 5 cases being misdiagnosed as cancer. This misdiagnosis may be due to the fact that SH tissues have less glandular and ductal components, and low Citlevels, meaning that the $\mathrm{CC} / \mathrm{C}$ value was increased.

There are limitations to the present study. First, because it is a retrospective study, there may be selection bias in the patient cohort. Second, the IPCa sample size was relatively small. Since the exact location of the occurrence of the incidental carcinoma could not be obtained by pathological examination following TURP, the CC/C values of all available voxels in the central gland were measured in the present study. Owing to the impact of the partial volume effect in sample slices, the measured $\mathrm{CC} / \mathrm{C}$ values may have been be slightly lower than those of the areas of cancer, although they could also reflect metabolic changes to IPCa. In addition, two methods were used to measure ADC values in the present study: The ADC value of the central gland and the minimal ADC value of the central gland. The two methods had advantages and disadvantages. Measuring the ADC value of the central gland, the ROI was drawn as large as possible, in accordance with the size of the central gland. The measured value was the ADC value of the central gland at this slice, including the cancerous and non-cancerous areas, and even calcification and bleeding within the ROI. Owing to the impact of the partial volume effect, measurement of the ADC value of the central gland could not reflect the real ADC value of the cancerous area, although use of this method was suitable when the lesion location could not be defined. The second method was to measure the minimal ADC value of the central gland, which avoided the partial volume effect $(5,9-11,17,18)$. The minimal ADC value of the cancerous tissue was lower than that of the normal tissue or benign lesion, which may reflect a more realistic $\mathrm{ADC}$ value.

Taken together, the results of the present study demonstrate that the performance characteristics of IPCa are similar to those of BPH on 3D MRS and DWI, meaning that IPCa cannot be distinguished preoperatively from 
BPH using current MRI examination techniques. Further and larger studies are required, however, to confirm these findings.

\section{Acknowledgements}

Not applicable.

\section{Funding}

The present study was supported by the funding from China Postdoctoral Science Foundation (grant no. 2016M592595).

\section{Availability of data and materials}

The datasets used and/or analyzed during the current study are available from the corresponding author on reasonable request.

\section{Authors' contribution}

JL and QZ guaranteed the integrity of the study. XQZ, XRY and JL were involved in study conceptrion and design. ZLD and XFM conducted the clinical studies and data analysis. XQZ and XRY were involved in manuscript preparation. QZ performed statistical analysis and edited the manuscript.

\section{Ethics approval and consent to participate}

Informed consent was waived by the Nantong Medical Institutional Review Board for this retrospective study.

\section{Consent for publication}

Not applicable.

\section{Competing interests}

The authors declare that they have no competing interests.

\section{References}

1. Mazzucchelli R, Barbisan F, Scarpelli M, Lopez-Beltran A, van der Kwast TH, Cheng L and Montironi R: Is incidentally detected prostate cancer in patients undergoing radical cystoprostatectomy clinically significant? Am J Clin Pathol 131: 279-283, 2009.

2. Chesnais AL, Niaf E, Bratan F, Mège-Lechevallier F, Roche $S$, Rabilloud M, Colombel M and Rouvière O: Differentiation of transitional zone prostate cancer from benign hyperplasia nodules: Evaluation of discriminant criteria at multiparametric MRI. Clin Radiol 68: e323-e330, 2013.

3. Oto A, Kayhan A, Jiang Y, Tretiakova M, Yang C, Antic T, Dahi F, Shalhav AL, Karczmar G and Stadler WM: Prostate cancer: Differentiation of central gland cancer from benign prostatic hyperplasia by using diffusion-weighted and dynamic contrast-enhanced MR imaging. Radiology 257: 715-723, 2010.

4. Hoeks CM, Hambrock T, Yakar D, Hulsbergen-van de Kaa CA, Feuth T, Witjes JA, Fütterer JJ and Barentsz JO: Transition zone prostate cancer: Detection and localization with 3-T multiparametric MR imaging. Radiology 266: 207-217, 2013.

5. Mazaheri Y, Shukla-Dave A, Hricak H, Fine SW, Zhang J, Inurrigarro G, Moskowitz CS, Ishill NM, Reuter VE, Touijer K, et al: Prostate cancer: Identification with combined diffusion-weighted MR imaging and 3D 1H MR spectroscopic imaging-correlation with pathologic findings. Radiology 246: 480-488, 2008.

6. Hoeks CM, Barentsz JO, Hambrock T, Yakar D, Somford DM, Heijmink SW, Scheenen TW, Vos PC, Huisman H, van Oort IM, et al: Prostate cancer: Multiparametric MR imaging for detection, localization and staging. Radiology 261: 46-66, 2011.
7. Bratan F, Niaf E, Melodelima C, Chesnais AL, Souchon R, Mège-Lechevallier F, Colombel M and Rouvière O: Influence of imaging and histological factors on prostate cancer detection and localisation on multiparametric MRI: A prospective study. Eur Radiol 23: 2019-2029, 2013.

8. Yoshizako T, Wada A, Hayashi T, Uchida K, Sumura M, Uchida N, Kitagaki $\mathrm{H}$ and Igawa M: Usefulness of diffusion-weighted imaging and dynamic contrast-enhanced magnetic resonance imaging in the diagnosis of prostate transition-zone cancer. Acta Radiol 49: 1207-1213, 2008.

9. Li B, Cai W, Lv D, Guo X, Zhang J, Wang X and Fang J: Comparison of MRS and DWI in the diagnosis of prostate cancer based on sextant analysis. J Magn Reson Imaging 37: 194-200, 2013.

10. Ren J, Huan Y, Wang H, Zhao H, Ge Y, Chang Y and Liu Y: Diffusion-weighted imaging in normal prostate and differential diagnosis of prostate diseases. Abdom Imaging 33: 724-728, 2008.

11. Manenti G, Squillaci E, Di Roma M, Carlani M, Mancino S and Simonetti G: In vivo measurement of the apparent diffusion coefficient in normal and malignant prostatic tissue using thin-slice echo-planar imaging. Radiol Med 111: 1124-1133, 2006 (In English, Italian).

12. Kim JH, Kim JK, Park BW, Kim N and Cho KS: Apparent diffusion coefficient: Prostatecancer versus noncancerous tissue according to anatomical region. J Magn Reson Imaging 28: 1173-1179, 2008.

13. Mian BM, Lehr DJ, Moore CK, Fisher HA, Kaufman RP Jr, Ross JS, Jennings TA and Nazeer T: Role of prostate biopsy schemes in accurate prediction of Gleason scores. Urology 67: 379-383, 2006.

14. Zakian KL, Eberhardt S, Hricak H, Shukla-Dave A, Kleinman S, Muruganandham M, Sircar K, Kattan MW, Reuter VE, Scardino PT and Koutcher JA: Transition zone prostate cancer: Metabolic characteristics at $1 \mathrm{H}$ MR spectroscopic imaging-initial results. Radiology 229: 241-247, 2003.

15. Mueller-Lisse UG and Scherr MK: Proton MR spectroscopy of the prostate. Eur J Radiol 63: 351-360, 2007.

16. Wu LM, Xu JR, Gu HY, Hua J, Chen J, Zhang W, Zhu J, Ye YQ and $\mathrm{Hu}$ J: Usefulness of diffusion-weighted magnetic resonance imaging in the diagnosis of prostate cancer. Acad Radiol 19: 1215-1224, 2012.

17. Issa B: In vivo measurement of the apparent diffusion coefficient in normal and malignant prostatic tissues using echo-planar imaging. J Magn Reson Imaging 16: 196-200, 2002.

18. Gibbs P, Pickles MD and Turnbull LW: Diffusion imaging of the prostate at 3.0 tesla. Invest Radiol 41: 185-188, 2006.

19. Merrill RM and Wiggins CL: Incidental detection of populationbased prostate cancer incidence rates through transurethral resection of the prostate. Urol Oncol 7: 213-219, 2002.

20. Yang XY, Xia TL, He Q, Li W, Wang JH, Su JW, Li J and Na YQ: Incidence and pathological features of incidental prostate cancer and clinical significance thereof. Zhonghua Yi Xue Za Zhi 87: 2632-2634, 2007 (In Chinese).

21. Melchior S, Hadaschik B, Thüroff S, Thomas C, Gillitzer R and Thüroff J: Outcome of radical prostatectomy for incidental carcinoma of the prostate. BJU Int 103: 1478-1481, 2009.

22. Joung JY, Yang SO, Seo HK, Kim TS, Han KS, Chung J, Park WS, Jeong IG and Lee KH: Incidental prostate cancer detected by cystoprostatectomy in Korean men. Urology 73: 153-157, 2009.

23. Akin O, Sala E, Moskowitz CS, Kuroiwa K, Ishill NM, Pucar D, Scardino PT and Hricak H: Transition zone prostate cancers: Features, detection, localization, and staging at endorectalMR imaging. Radiology 239: 784-792, 2006.

24. Wang XZ, Wang B, Gao ZQ, Liu JG, Liu ZQ, Niu QL, Sun ZK and Yuan YX: 1H-MRSI of prostate cancer: The relationship between metabolite ratio and tumor proliferation. Eur J Radiol 73: 345-351, 2010

25. Sato $C$, Naganawa $S$, Nakamura $T$, Kumada $H$, Miura $S$, Takizawa $\mathrm{O}$ and Ishigaki T: Differentiation of noncancerous tissue and cancer lesions by apparent diffusion coefficient values in transition and peripheral zones of the prostate. J Magn Reson Imaging 21: 258-262, 2005.

26. Gibbs P, Tozer DJ, Liney GP and Turnbull LW: Comparison of quantitative T2 mapping and diffusion-weighted imaging in the normal and pathologic prostate. Magn Reson Med 46: 1054-1058, 2001.

27. Pickles MD, Gibbs P, Sreenivas M and Turnbull LW: Diffusionweighted imaging of normal and malignant prostate tissue at 3.0T. J Magn Reson Imaging 23: 130-134, 2006. 
28. Montironi R, Mazzucchelli R, Santinelli A, Scarpelli M, Beltran AL and Bostwick DG: Incidentally detected prostate cancer in cystoprostatectomies: Pathological and morphometric comparison with clinically detected cancer in totally embedded specimens. Hum Pathol 36: 646-654, 2005.

29. Montironi R, Mazzucchelli R, Barbisan F, Stramazzotti D, Santinelli A, Scarpelli M and Lòpez Beltran A: HER2 expression and gene amplification in pT2a Gleason score 6 prostate cancer incidentally detected in cystoprostatectomies: Comparison with clinically detected androgen-dependent and androgen-independent cancer. Hum Pathol 37: 1137-1144, 2006.
30. Noworolski SM, Vigneron DB, Chen AP and Kurhanewicz J: Dynamic contrast-enhanced MRI and MR diffusion imaging to distinguish between glandular and stromal prostatic tissues. Magn Reson Imaging 26: 1071-1080, 2008.

31. García-Segura JM, Sánchez-Chapado M, Ibarburen C, Viaño J, Angulo JC, González J and Rodríguez-Vallejo JM: In vivo proton magnetic resonance spectroscopy of diseased prostate: Spectroscopic features of malignant versus benign pathology. Magn Reson Imaging 17: 755-765, 1999. 